\title{
PERSPECTIVE \\ Ethical Questions in Medical Electronic Adherence Monitoring
}

\author{
Jeffrey I. Campbell, BA ${ }^{7}$, Nir Eyal, DPhil , Angella Musiimenta, PhD ${ }^{3}$, and Jessica E. Haberer, MD ${ }^{4,5}$ \\ ${ }^{1}$ Center for Bioethics, Harvard Medical School, Boston, MA, USA; ${ }^{2}$ Department of Global Health and Population, Harvard T.H. Chan School of Public \\ Health, Boston, MA, USA; ${ }^{3}$ Department of Information Technology, Mbarara University of Science and Technology, Mbarara, Uganda; ${ }^{4}$ Center for \\ Global Health, Massachusetts General Hospital, Boston, MA, USA; ${ }^{5}$ epartment of Medicine, Harvard Medical School, Boston, MA, USA.
}

Electronic adherence monitors (EAMs) record and report an array of health behaviors, ranging from taking daily medications to wearing medical devices. EAMs are utilized in research worldwide and are being investigated for clinical use. However, there is also growing popular concern about the extent to which electronic devices may be used to monitor individuals, including allegations in the media that EAMs represent a move towards "Big Brother" in medicine. Here, we highlight the unique benefits as well as the potential ethical challenges that electronic adherence monitoring generates. These challenges surround autonomy, privacy and confidentiality, trust, and ancillary care obligations. We describe key questions within each of these domains that warrant further investigation, and present potential solutions to many of the concerns raised.

KEY WORDS: electronic adherence monitoring; patient adherence; privacy; confidentiality; personal autonomy; research ethics.

J Gen Intern Med 31(3):338-42

DOI: $10.1007 / \mathrm{s} 11606-015-3502-4$

(c) Society of General Internal Medicine 2015

\section{INTRODUCTION}

Many technologies now exist that enable remote health monitoring, ranging from personal vital sign monitors that promote fitness to video cameras that detect falls among the elderly. While these devices may play an important role in health, they also generate potential ethical concerns, chiefly raising the specter of "Big Brother" 1,2 - invasive monitoring by organizations or individuals in positions of authority. Prior literature on such technologies has identified key ethical considerations, including privacy and autonomy, ${ }^{3,4}$ and the balance between them and the goal of improving health. ${ }^{4}$

Electronic adherence monitors (EAMs) are a subset of these technologies that aim to document, specifically, how well an individual follows medical guidance. For example, medication bottles can be fitted with electronic caps that record time-anddate stamps whenever the bottle cap is removed, providing objective data that function as surrogate indicators of adherence. Similarly, electronic apnea mask monitors measure how

Received January 20, 2015

Revised May 15, 2015

Accepted August 14, 2015

Published online September 10, 2015 frequently the mask is used at night. Other examples are listed in Table 1.

EAMs reduce uncertainty about adherence measurements, both by avoiding recall bias (i.e., challenges in recalling daily adherence events) and by minimizing social desirability bias (i.e., preferential reporting of information that an individual believes a researcher wants to hear). Some devices report adherence in real time, allowing researchers to investigate adherence problems as they occur. ${ }^{5}$ EAMs are utilized primarily in research settings, although use in clinical care is increasing.

EAMs raise specific ethical concerns that are distinct from those raised by other electronic monitoring devices and by non-electronic adherence monitoring strategies (e.g., directly observed therapy). Principally, the continuous presence of EAMs in an individual's private life and their relative ease of integration into his or her daily routines and environments enable an unprecedented view of day-to-day activities. Furthermore, unlike fall detectors and many other telemedicine devices designed to monitor routine activities and events, EAMs are designed to monitor taking of prescribed medications or other behaviors, introducing considerations about control and power dynamics between prescribers and users.

In this article, we discuss four concerns with specific relevance for and application to EAMs: 1) autonomy, 2) privacy and confidentiality, 3) trust in patients, and 4) ancillary care obligations. We identify preliminary philosophical responses and practical solutions to these challenges, and raise questions for future investigation.

\section{Autonomy}

Adherence monitoring may limit an individual's liberty to be non-adherent, and in that sense, limit her autonomy. ${ }^{1}$ Adherence monitoring may also limit liberty more generally, because the researcher's or practitioner's (perceived) omnipresent gaze may undermine an individual's autonomy to behave in ways construed as non-normative, embarrassing, or simply private. While some empirical studies of e-surveillance devices (e.g., home fall monitors) suggest that individuals can gain a sense of freedom from monitoring, ${ }^{6}$ other individuals describe a need to hide themselves from the device and thereby avoid observation. ${ }^{7}$ Although patients can deceive clinicians or researchers with some EAMs (e.g., a patient may open the lid of an electronically equipped pill box without removing 
Table 1 Examples of EAM Devices and the Illnesses They Have Been Used to Study

\begin{tabular}{|c|c|}
\hline Electronic adherence monitor & Examples of illnesses studied \\
\hline Electronic medication containers & $\begin{array}{l}\text { HIV, diabetes, cancer, } \\
\text { hypertension, lupus }\end{array}$ \\
\hline $\begin{array}{l}\text { Real-time electronic medication } \\
\text { containers }\end{array}$ & HIV, tuberculosis \\
\hline Electronic blister packs & $\begin{array}{l}\text { Post-transplant immune } \\
\text { suppression, hypertension }\end{array}$ \\
\hline Electronic braces & Scoliosis \\
\hline Electronic nebulizers & $\begin{array}{l}\text { Smoking-related pulmonary } \\
\text { disease, cystic fibrosis }\end{array}$ \\
\hline Electronic inhalers & Asthma \\
\hline $\begin{array}{l}\text { Electronic continuous positive } \\
\text { airway pressure masks }\end{array}$ & Sleep apnea \\
\hline Electronic auto-injectors & Multiple sclerosis \\
\hline $\begin{array}{l}\text { Monitoring-enabled vibration } \\
\text { platforms }\end{array}$ & Multiple sclerosis \\
\hline
\end{tabular}

any pills), other EAMs, like continuous positive airway pressure (CPAP) monitors ${ }^{8}$ and recently approved pill monitors that document ingestion, ${ }^{9}$ may preclude this option.

We suggest two philosophical responses and one practical response to concerns about autonomy. First, if the individual's choice to continue using the EAM is voluntary, it is usually safe to assume that she genuinely wants to be more adherent, and thus, when she succeeds in doing so, that EAMs help her fulfill her own autonomous will. ${ }^{10}$ This response is irrelevant in situations in which individuals choose to forgo therapy, such as therapy perceived to be futile or too toxic. One could also argue that what the EAM user "loses" while using the EAM-primarily the freedom to remain sick or untreated-is of little objective value to the individual. ${ }^{11}$

Second, even if EAM use requires forfeiting a measure of autonomy, a requirement of explicit informed consent for EAM use (or opt-in use) could preserve autonomous control. ${ }^{12}$ Analogously, in so-called Ulysses contracts (future-oriented self-binding contracts, such as some advance directives), individuals voluntarily sacrifice a measure of future freedom, and the voluntary nature of the sacrifice can preserve overall autonomy. ${ }^{13}$ Informed consent is the standard in research and could be instituted in clinical EAM care as well, although it would potentially create a barrier to EAM use in busy clinical settings. Admittedly, some diseases may be of such severity, and adherence of such priority (e.g., post-transplant immune suppression), that patients who are offered EAMs may have no real choice but to use them. In such instances, however, the remaining challenge to autonomy would ultimately stem not from electronic monitoring but from the lack of acceptable alternatives to improving adherence.

Third, the importance of employing an EAM to improve adherence or researchers' understanding of adherence may override concerns about minor losses of autonomy. Overcoming disease may matter more than optimal autonomy. And even when patients perceive surveillance as a form of control, they may still view it positively, e.g., as providing "guardianship". ${ }^{14}$

\section{Privacy and Confidentiality}

Concerns about privacy herein refer to researchers' or clinicians' access to information about EAM users beyond the specific behavior being monitored. For example, EAMs may give researchers a basis for forming assumptions about users' personal habits that would, in high likelihood, occur with use of the EAM. In a study of electronic scoliosis brace monitoring in a pediatric population, researchers speculated that one (unidentified) participant's brace removal, which occurred regularly in the morning, reflected times that she was bathing. ${ }^{15}$ Such access may be perceived as privacy transgression. In a study assessing acceptability of an EAM for measuring antimalarial bednet use in Uganda, one respondent described concern about researchers observing her while she slept, although the device had no capacity to do so. ${ }^{16}$ And in a study of telemonitoring, participants described thinking of ways to cover monitoring devices in order to avoid being watched within the private confines of their homes. ${ }^{7}$ EAM users and even researchers may not be aware of what behaviors are being monitored until the devices' records are analyzed.

In contrast to privacy, confidentiality herein pertains to outsiders' access to personal health information that EAMs reveal. One primary risk associated with EAMs is the potential for unintended disease status disclosure - a greater concern for stigmatized illnesses like HIV than for most other conditions. Our group is studying EAMs in rural Uganda, where most technology is readily noticed, and EAMs are being used exclusively for studying HIV/AIDS. There, the device has led to unintended disclosure of HIV status, and concern about disclosure has arisen in other studies as well. ${ }^{17}$ However, the devices have also created a positive opportunity to enable desired disclosure. ${ }^{18}$

EAMs' definitional reliance upon electronic data creates the potential for breaches in confidentiality through security breaches. Blanket regulations, such as the U.S. Health Insurance Portability and Accountability Act (HIPAA) privacy and security rules, ${ }^{19}$ may protect the electronic data that EAMs collect, but as recent prominent security breaches have shown, electronic data is at risk even in settings with strictly enforced protections. ${ }^{20}$ And EAMs are frequently used in parts of the world where electronic health data are not stringently regulated. ${ }^{21}$

The extent to which someone tolerates loss of privacy or confidentiality is culturally and individually relative. ${ }^{22}$ For instance, while HIV patients in India and Malawi ${ }^{23}$ and in the United States ${ }^{24}$ have expressed concerns that electronic pill bottles could raise suspicion from family and neighbors, such concerns were not raised by HIV patients in Uganda, ${ }^{5}$ Tanzania, ${ }^{10}$ or South Africa. ${ }^{25}$ The heterogeneous findings of these studies may reflect variations in individual or cultural conceptualization of privacy and confidentiality, in criteria for 
what counts as a breach, or differences in disease-associated stigma.

We identify three possible practical responses to concerns about privacy and confidentiality. First, deliberately using similar EAM devices not only for stigmatized diseases (like HIV) but also for relatively non-stigmatized diseases (like hypertension) would help disguise who has the stigmatized disease in settings where these devices are highly visible and unique, and therefore likely to attract attention. Second, in clinical settings, creating explicit informed consent procedures for EAMs may preempt both privacy and confidentiality concerns by ensuring that individuals authorize any sharing of information. Third, a blinded-monitoring approach in which a third-party aide with no personal contact with research subjects or patients reviews adherence data might mitigate privacy concerns. Automated monitoring, in particular, could remove potential feelings of judgment.

\section{Trust}

Trust is vital in patient-provider and participant-researcher relationships, and may itself increase adherence. ${ }^{26}$ Constant monitoring for perceived adherence lapses carries a risk of suggesting to individuals that they have something to hide ${ }^{27}$ or that their reports of adherence cannot be fully trusted. A1though not infallible, EAMs provide objective measures of adherence that are typically more accurate than self-reported information. ${ }^{28}$ Reported results can contradict instances when individuals subjectively report to have taken medication (e.g., suggesting social desirability bias), which may damage the patient-provider or participant-researcher relationship. In a study of an EAM to monitor health care providers' use of hand sanitizers, one participant (a medical provider in that case) complained about being monitored, potentially protesting perceived distrust: "Why do we need to be treated like kindergartners? I'm a professional". 29

We identify one philosophical and one practical response to these concerns. First, some perceived mistrust may be an acceptable cost of studying or optimizing adherence. The harms incurred from a slight reduction in trust could be substantially outweighed by the benefits of adherence. For example, small deficits in trust need not impair the functioning of a clinician's relationship with the patient, but may enable small improvements in adherence that prevent significant negative health outcomes (e.g., development of ARV resistance). A second practical solution to these concerns may be seen in devices that facilitate patient self-monitoring (e.g., pill bottles that display the number of cap openings to patients ${ }^{30}$ ). This may convert the device from a tool solely designed for data gathering to an adherence tool that empowers users to better monitor their own choices. Notably, some consumer products that could be considered EAMs, such as commercially available activity monitors, complete this transition by making the

Table 2 Key Ethical Challenges, Related Questions, and Potential Solutions in EAM Research and Clinical Practice

\begin{tabular}{|c|c|c|}
\hline Ethics domain & Theoretical questions & Potential practical solutions for further consideration \\
\hline Autonomy & $\begin{array}{l}\text { - Does frequent or continuous adherence monitoring } \\
\text { threaten autonomy more than patient self-reporting? } \\
\text { - Does simply observing adherence with an EAM } \\
\text { (instead of intervening based on EAM data) impact } \\
\text { autonomy? } \\
\text { - Can simply monitoring adherence be coercive? } \\
\text { - Do public health concerns about infectious diseases } \\
\text { trump concerns about autonomy? }\end{array}$ & - Opt-in use of EAMs (vs. opt-out or mandatory use) \\
\hline Privacy and confidentiality & $\begin{array}{l}\text { - Does monitoring threaten the putative right to } \\
\text { withhold personal details from providers? } \\
\text { - How much do users authorize loss of privacy when } \\
\text { consenting to the use of EAMs? } \\
\text { - What minimum data security precautions should } \\
\text { health officials, researchers, and clinicians adopt to } \\
\text { protect EAM data in the absence of local government } \\
\text { regulations? } \\
\text { - How might researchers address privacy concerns } \\
\text { arising from covert monitoring, even if consent is } \\
\text { granted retroactively? } \\
\text { - How do local cultural attitudes affect perceptions } \\
\text { of threat to privacy and confidentiality? } \\
\text { - Do EAMs change local concepts of privacy and } \\
\text { confidentiality? }\end{array}$ & $\begin{array}{l}\text { - Informed consent (including in clinical practice) } \\
\text { - Adoption of EAMs to monitor multiple diseases in } \\
\text { settings where devices might be associated with a } \\
\text { stigmatized illness (e.g., HIV) } \\
\text { - Tailoring devices to local privacy concerns } \\
\text { - Third-party blinded monitoring }\end{array}$ \\
\hline Trust & $\begin{array}{l}\text { - Do EAMs imply mistrust of a patient's word? } \\
\text { - Could the threat from perceived mistrust to patient- } \\
\text { provider concordance be so great as to render EAMs } \\
\text { unwarranted? }\end{array}$ & $\begin{array}{l}\text { - Devices that facilitate feedback to individuals } \\
\text { (e.g., devices with built-in reminder systems) }\end{array}$ \\
\hline Ancillary care obligations & $\begin{array}{l}\text { - How much are researchers responsible for addressing } \\
\text { non-adherence detected by EAMs? } \\
\text { - What characteristics of the risks of non-adherence, } \\
\text { study design, consent process, etc., influence this } \\
\text { responsibility? } \\
\text { - How much does advanced disclosure of lack of intention } \\
\text { to intervene (e.g., during the informed consent) mitigate } \\
\text { researchers' responsibilities? }\end{array}$ & $\begin{array}{l}\text { - Informed consent } \\
\text { - Use of relatively inexpensive or low-intensity } \\
\text { interventions (e.g., text message reminders) when } \\
\text { non-adherence is detected }\end{array}$ \\
\hline
\end{tabular}


user both the monitor and the monitored. These devices create potential for adherence monitoring by marketing firms or other commercial enterprises - new dynamics that will need to be examined as they evolve. Finally, monitoring may also enhance relationships with health providers and researchers, ${ }^{31}$ perhaps mediated through an increased perception of trust when the objective indication of adherence makes an EAM user appear responsible and trustworthy.

\section{Ancillary Care Obligations}

When an EAM detects non-adherence in a research study, this information becomes available to researchers, sometimes in real time. ${ }^{32}$ Researchers then possess potentially actionable health information. To what extent must they address the nonadherence that EAMs detect? The data that EAMs collect pose a unique strain on obligations of ancillary care (that is, for care that research participants need but that goes beyond what is required in order to conduct the study). Because of resource limitations and the large amount of data that EAMs collect, researchers (and clinicians) will almost certainly lack the capacity and the financial resources to act immediately on all instances of detected non-adherence. That includes nonadherence with potentially significant clinical implications such as development of antiretroviral resistance among HIV patients.

We see one philosophical and two practical potential responses to this challenge. Although research participants may tacitly entrust components of their healthcare to researchers, who thereby acquire some duties to provide related ancillary care, the "scope of entrustment" has been said to depend on the study aim or design. ${ }^{33}$ Therefore, researchers might not always be obliged to intervene in cases of identified nonadherence.

Practically, the nature of intervention in response to nonadherence may vary even when obligations to intercede exist. Overburdened investigators could, for instance, partner with local health systems to alert providers without responding to non-adherence directly. ${ }^{34}$ In addition, the development and promotion of low-intensity adherence interventions (e.g., home visits or text messages when non-adherence is detected $^{35-37}$ ) as part of EAM-based research studies could address the challenges associated with frequent intervention without imposing onerous demands on investigators or clinicians.

\section{SUMMARY}

As researchers, and increasingly clinicians and policymakers, decide when and how to use EAMs, philosophical and practical responses to the ethical challenges that these technologies raise will be necessary. This analysis identifies ethical challenges surrounding autonomy, privacy and confidentiality, trust, and ancillary care obligations. Understanding the basic ethical challenges, as well as possible solutions, will help improve the experience of using these devices and preempt later dilemmas and harms.

Empirical work exploring individuals' attitudes towards the challenges and potential solutions is needed. Preliminary questions to guide further research are presented in Table 2. Studies on attitudes towards the use of EAMs could guide clinical-, research- and policy-level recommendations on best use of these devices. In particular, empirical studies should reflect the broad geographic and cultural contexts within which EAMs are being used, reflecting the variety of attitudes in these disparate environments. As new health monitoring technologies continue to emerge, such guidance becomes all the more pressing.

Acknowledgments: We would like to thank Dr. David Bangsberg and Dr. Daniel Wikler for their input and mentorship.

Prior Presentations: An early version of this article was presented at the American Society of Bioethics and Humanities annual conference in San Diego, California, October 16-19, 2014.

Competing Interests: The authors declare that they do not have a conflict of interest.

Funding: All authors received support from the National Institute of Allergy and Infectious Diseases (R21AI108329-01). The study funders had no role in study design, decision to publish, or preparation of the manuscript.

Author Contributions: Conceived and wrote the paper: JIC, NE, AM, JEH

Corresponding Author: Nir Eyal, DPhil; Department of Global Health and PopulationHarvard T.H. Chan School of Public Health, Boston, MA, USA (e-mail: nir_eyal@hms.harvard.edu).

\section{REFERENCES}

1. Rand CS, Sevick MA. Ethics in adherence promotion and monitoring. Control Clin Trials. 2000;21:241S-7S.

2. Rapoff MA. Adherence to pediatric medical regimens. New York: Kluwer Academic/Plenum Publishers; 1999.

3. Ganyo M, Dunn M, Hope T. Ethical issues in the use of fall detectors. Ageing Soc. 2011;31(08):1350-67. doi:10.1017/S0144686X10001443.

4. Percival J, Hanson J. Big brother or brave new world? Telecare and its implications for older people's independence and social inclusion. Crit Soc Policy. 2006;26(4):888-909. doi:10.1177/0261018306068480.

5. Haberer JE, Kahane J, Kigozi I, Emenyonu N, Hunt P, Martin J, et al. Real-time adherence monitoring for HIV antiretroviral therapy. AIDS Behav. 2010;14(6):1340-6. doi:10.1007/s10461-010-9799-4.

6. Essen A. The two facets of electronic care surveillance: an exploration of the views of older people who live with monitoring devices. Soc Sci Med. 2008;67(1):128-36. doi:10.1016/j.socscimed.2008.03.005.

7. Courtney KL, Demiris G, Hensel BK. Obtrusiveness of information-based assistive technologies as perceived by older adults in residential care facilities: a secondary analysis. Med Inform Internet Med. 2007;32(3):2419. doi: 10.1080/14639230701447735.

8. Kribbs NB, Pack AI, Kline LR, Smith PL, Schwartz AR, Schubert NM, et al. Objective measurement of patterns of nasal CPAP use by patients with obstructive sleep apnea. Am Rev Respir Dis. 1993;147(4):887-95. doi:10.1164/ajrccm/147.4.887.

9. DiCarlo LA. Role for direct electronic verification of pharmaceutical ingestion in pharmaceutical development. Contemp Clin Trials. 2012;33(4):593-600. doi:10.1016/j.cct.2012.03.008.

10. Lyimo RA, van den Boogaard J, Msoka E, Hospers HJ, van der Ven A, Mushi D, et al. Measuring adherence to antiretroviral therapy in northern 
Tanzania: feasibility and acceptability of the medication event monitoring system. BMC Public Health. 2011;11:92. doi:10.1186/1471-2458-11-92.

11. Raz J. The Morality of Freedom. Oxford: Clarendon; 1986.

12. Beauchamp TL. In: Miller F, Wertheimer R, eds. "Consent and Autonomy." The Ethics of Consent. New York: Oxford University Press; 2010:55-78.

13. Elster J. Ulysses and the Sirens: studies in rationality and irrationality. New York, NY: Cambridge University Press; 1984.

14. Bogard W. Surveillance assemblages and lines of flight. In: Lyon D, ed. Theorizing surveillance: the panopticon and beyond. Devon, UK: Willan Publishing; 2006:97-122.

15. Nicholson GP, Ferguson-Pell MW, Smith K, Edgar M, Morley T. The objective measurement of spinal orthosis use for the treatment of adolescent idiopathic scoliosis. Spine. 2003;28(19):2243-50. doi:10.1097/ 01.BRS.0000085098.69522.52. discussion 50-1.

16. Krezanoski P, Santorino D, Campbell J, Nambogo N. Maternal acceptability of objective monitoring of household bednet use in Uganda. Proceedings of the 63rd Annual Meeting of the American Society of Tropical Medicine and Hygiene; New Orleans, LA, November 2-6, 2014.

17. Bachman Desilva M, Gifford AL, Keyi X, Li Z, Feng C, Brooks M, et al. Feasibility and acceptability of a real-time adherence device among HIVpositive IDU patients in China. AIDS Res Treat. 2013;2013:957862. doi:10. $1155 / 2013 / 957862$.

18. Pisarski E, Wyatt M, Tam M, Atukunda E, Musiimenta A, Haberer J, et al. Experiences of Wisepill-Facilitated HIV Disclosure in Rural Southwestern Uganda. Proceedings of the 10th International Conference on HIV Treatment and Prevention Adherence. Miami, FL, June 28-30, 2015.

19. United States. Health Insurance Portability and Accountability Act of 1996. Public Law 104-191. United States statutes at large. 1996;110:1936-2103.

20. Abelson R, Goldstein M. Millions of Anthem Customers Targeted in Cyberattack. New York Times. February 5, 2015; Sect. B:1. Accessed online at: http://www.nytimes.com/2015/02/05/business/hackers-breacheddata-of-millions-insurer-says.html. Last accessed July 1, 2015.

21. Townsend B. mHealth Regulation Impact Assessment: Africa. Accessed online at: http://www.gsma.com/mobilefordevelopment/wp-content/ uploads/2015/03/003-GSMA-RIA-Africa-27feb 15.pdf. Last accessed July 1, 2015. Sponsored by the Groupe Speciale Mobile Association.

22. Moore A. Privacy: its meaning and value. Am Philos Q. 2003;40:215-27.

23. Safren SA, Kumarasamy N, Hosseinipour M, Harwood MM, Hoffman I, McCauley M, et al. Perceptions about the acceptability of assessments of HIV medication adherence in Lilongwe, Malawi and Chennai. India AIDS Behav. 2006;10(4):443-50. doi:10.1007/s10461-006-9094-6.

24. Konkle-Parker DJ, Erlen JA, Dubbert PM. Lessons learned from an HIV adherence pilot study in the Deep South. Patient Educ Couns. 2010;78(1):91-6. doi:10.1016/j.pec.2009.04.010.

25. van der Straten A, Montgomery E, Pillay D, Cheng H, Naidoo A, Cele Z, et al. Feasibility, performance, and acceptability of the Wisebag for potential monitoring of daily gel applicator use in Durban. South Africa AIDS Behav. 2013;17(2):640-8. doi:10.1007/s10461-012-0330-y.

26. Thom DH, Hall MA, Pawlson LG. Measuring patients' trust in physicians when assessing quality of care. Health Aff. 2004;23(4):124-32.

27. Wolff J. Fairness, respect and the egalitarian ethos. Philos Publ Affairs. 1998;27:97-122.

28. Simoni JM, Montgomery A, Martin E, New M, Demas PA, Rana S. Adherence to antiretroviral therapy for pediatric HIV infection: a qualitative systematic review with recommendations for research and clinical management. Pediatrics. 2007;119(6):e1371-83. doi:10. 1542/peds.2006-1232.

29. Ellingson K, Polgreen PM, Schneider A, Shinkunas L, Kaldjian LC, Wright $\mathbf{D}$, et al. Healthcare personnel perceptions of hand hygiene monitoring technology. Infect Control Hospital Epidemiol : Off J Soc Hospital Epidemiol Am. 2011;32(11):1091-6. doi:10.1086/662179.

30. Robin AL, Novack GD, Covert DW, Crockett RS, Marcic TS. Adherence in glaucoma: objective measurements of once-daily and adjunctive medication use. Am J Ophthalmol. 2007;144(4):533-40. doi:10.1016/j.ajo. 2007.06.012.

31. Mittelstadt B, Fairweather B, Shaw M, McBride N. The ethical implications of personal health monitoring. Int $J$ Technoethics (IJT). 2014;5(2):3760.

32. Haberer JE, Kiwanuka J, Nansera D, Muzoora C, Hunt PW, So J, et al. Realtime adherence monitoring of antiretroviral therapy among HIVinfected adults and children in rural Uganda. Aids. 2013;27(13):2166-8. doi:10.1097/QAD.0b013e328363b53f.

33. Richardson H. Moral Entanglements: The Ancillary-Care Obligations of Medical Researchers. New York: Oxford University Press; 2012.

34. Participants in Georgetown University Workshop on Ancillary-Care Obligations of Medical Researchers Working in Developing Countries. The ancillary-care obligations of medical researchers working in developing countries. PLoS Medicine. 2008;5(5):e90. doi:10.1371/journal.pmed. 0050090

35. Vervloet $M$, van Dijk $L$, Santen-Reestman $J$, van Vlijmen $B$, van Wingerden P, Bouvy ML, et al. SMS reminders improve adherence to oral medication in type 2 diabetes patients who are real time electronically monitored. Int J Med Inform. 2012;81(9):594-604. doi:10.1016/j.ijmedinf. 2012.05.005.

36. Hettinga M, Gutter T, te Gussinklo J. Real Time Medication Monitoring with customized SMS reminders for people with refractory epilepsy. eTELEMED 2013, The Fifth International Conference on eHealth, Telemedicine, and Social Medicine. Nice, FR, February 24 - March 1, 2013.

37. Lester RT, Ritvo P, Mills EJ, Kariri A, Karanja S, Chung MH, et al. Effects of a mobile phone short message service on antiretroviral treatment adherence in Kenya (WelTel Kenya1): a randomised trial. Lancet. 2010;376(9755):1838-45. doi:10.1016/S0140-6736(10)61997-6. 